\title{
AVALIAÇÃO QUANTITATIVA DA CONTAMINAÇÃO POR MICRO- ORGANISMOS NO AMBIENTE DE CRIAÇÃO DO BICHO-DA- SEDA (BOMBYX MORI L.) NA FASE DE CHOCADEIRA
}

\author{
L.F.F. Margatho, F. Okamoto, A.M. Almeida, C.A.J.P. Santos*
}

${ }^{1}$ Polo Regional de Desenvolvimento Tecnológico dos Agronegócios do Centro Oeste, Av. Rodrigues Alves, 40-40, CEP 17030-000, Bauru, SP, Brasil. E-mail: margatho@apta.sp.gov.br

\section{RESUMO}

\begin{abstract}
O objetivo do presente trabalho foi avaliar a contaminação bacteriana e fúngica em chocadeira antes e após procedimento de limpeza e desinfecção. Foram coletadas amostras do ar e de superfícies do piso, da parede, das folhas de amoreira, das lagartas do bicho-da-seda e da máquina picadeira de folhas. A metodologia empregada seguiu a técnica da placa de sedimentação e contato de superfície com meios de cultura específicos, Ágar Nutriente, Ágar McConkey e Ágar Sabouraud Dextrose para crescimento, respectivamente, de bactérias, de enterobactérias e de fungos. Os resultados demonstraram, ao término dos dois primeiros ínstars, aumento nos índices de contaminação fúngica e bacteriana nas superfícies das lagartas do bicho-da-seda, do piso e das folhas de amoreira. A limpeza e desinfecção reduziram o grau de contaminação por micro-organismos presentes no ambiente, do nível péssimo para o excelente. As folhas de amoreira representaram um forte potencial de infecção para as lagartas do bicho-da-seda. A contagem de colônias fúngicas e bacterianas foi uma forma simples de monitorar e detectar os pontos de problemas sanitários da chocadeira.
\end{abstract}

PALAVRAS-CHAVE: Desinfecção, entomopatógenos, placa de sedimentação.

\section{ABSTRACT}

QUANTITATIVE EVALUATION OF BIOLOGICAL AND ENVIROMENTAL CONTAMINATION BY MICROORGANISMS ON THE SURFACE AND IN THE AIR OF INCUBATORY FOR SILKWORMS (BOMBYX MORI L.). The aim of this study was to evaluate the fungus and bacterial contamination in the silkworm incubatory before and after cleaning and disinfection procedures. Samples from the air and the surface of the floor, walls, mulberry leaves, silkworms, and leaf-trimming machine were collected. The methodology used was the sedimentation plate technique and surface contact with specific culture media such as Nutrient's agar, McConkey's agar and Sabouraud dextrose agar for growth, respectively, of bacteria, enterobacteria and fungi. The results showed that at the end of the two first instars, the fungus and bacterium index on the surface of the floor, the silkworm caterpillar and mulberry leaves had increased. The cleaning and disinfection reduced the level of contamination by microorganisms in the environment from very bad to excellent. The mulberry leaves represented a strong infection potential for the silkworm caterpillar. The counting of bacteria and fungus colonies was a very simple way of monitoring and detecting the incubatory sanitary problems.

KEY WORDS: Disinfection, entomopathogenic, sedimentation plates.

\section{INTRODUÇÃO}

No ciclo biológico do bicho-da-seda (Bombyx mori L.) o período larval, que compreende cinco idades ou ínstars, normalmente vai de 27 a 32 dias, desde a eclosão até a subida no bosque. Em exploração comercial, os dois primeiros ínstars ou idades da fase larval são conduzidos pelas Empresas de Fiação de Seda, em instalações conhecidas como chocadeiras.
Estas são usadas para obtenção de uma padronização na qualidade das lagartas, através do controle das condições ambientais e do manejo alimentar, estando a sanidade das lagartas diretamente relacionada com o êxito na produção de casulos.

Impedir a ocorrência de infecções nas chocadeiras representa um grande desafio para pesquisadores, técnicos e microbiologistas, pois, muitas vezes, os entomopatógenos conseguem vencer as barreiras

*Bolsista FUNDAP, Acadêmica de Biologia, UNESP, campus de Bauru. 
sanitárias de segurança adotadas, colocando em risco as criações (KRISHNASWAMI et al., 1973; OKINO, 1982; FonSECA; FONSECA, 1988).

Variedade de bactérias e fungos são comumente encontradas nos ambientes de criações, sendo as mais frequentes e com alto potencial adaptativo às condições desfavoráveis do meio os Streptococcus sp., Staphylococcus sp., Klebsiella sp., Proteus sp., Escherichia coli, Bacillus thuringiensis, Beauveria bassiana, Aspergillus spp. (OKINO, 1982; MARGATHO et al., 1996; HABIB; ANDRADE, 1998; PraÇA et al., 2004). Aspergillus fumigatus é um importante agente micótico nas fases iniciais, primeiro e segundo ínstars, do processo de criação, acarretando enormes perdas econômicas devido à mortalidade de lagartas. Estes estão presentes em diversos ambientes podendo ser introduzidos e disseminados rapidamente em chocadeiras, se não houver um sistema de desinfecção adequado (Tinoco; Almeida, 1992).

A qualidade e sanidade das larvas de terceiro ínstar entregues ao produtor são determinadas pela interação de múltiplos fatores, que precisam ser conhecidos e padronizados dentro de um sistema de controle que permita uma avaliação rotineira. $\mathrm{O}$ monitoramento microbiológico pode ser realizado por meio de exposição de placas e por contato, que são as técnicas mais utilizadas pela sua eficiência, simplicidade e baixo custo (Pelczar et al., 1997; TESSARI et al., 2002).

No Brasil, são escassos os dados referentes à determinação das condições sanitárias de chocadeiras destinadas ao bicho-da-seda. Almeida et al. (2003) demonstraram que os números médios de colônias de bactérias e fungos nestes locais são elevados, indicando que programas de controle sanitário devem ser implantados, para determinar os pontos estratégicos de biossegurança.

Portanto, o presente trabalho, através da amostragem do ar pela exposição de placas e contato em superfícies, objetivou detectar os locais e níveis de contaminações no ambiente por bactérias e fungos, além de avaliar a ação da limpeza e desinfecção em uma chocadeira destinada à exploração sericícola.

\section{MATERIAL E MÉTODOS}

O experimento foi desenvolvido na Unidade de Pesquisa e Desenvolvimento de Gália, localidade definida pelas coordenadas $22^{\circ} 18^{\prime}$ latitude sule $49^{\circ} 33^{\prime}$ longitude oeste, com temperatura média de $27^{\circ} \mathrm{C}$ e precipitação média anual de $1.100 \mathrm{~mm}$. O trabalho foi conduzido na instalação denominada chocadeira, com temperatura ambiente controlada para 26 a $28^{\circ} \mathrm{C}$ e umidade relativa do ar para 80 a $90 \%$.

As desinfecções foram realizadas com formol (comercializado em solução 37\%), preparada a 3\% e aplicada nas horas mais quentes do dia. Após a pulverização, a chocadeira permaneceu fechada por dois dias.

A amostragem para avaliação do índice de contaminação do ar foi efetuada através da técnica da placa de sedimentação ou técnica de exposição de placa. As placas de Petri contendo meios de cultura específicos, Ágar Nutriente (AN), Ágar McConkey e Ágar Sabouraud (AS) para contagem do número de Unidades Formadoras de Colônias (UFC), de bactérias, enterobactérias efungos, respectivamente, foram abertas e expostas em locais pré-determinados por cinco minutos para que ocorresse a sedimentação de partículas. Em seguida, foram fechadas e identificadas para serem examinadas no laboratório do Polo Regional do Centro Oeste, em Bauru, SP (GAmA et al., 1999; TESSARI et al., 2002).

\section{Técnica de contato}

A coleta por contato foi realizada sobre a superfície do bicho-da-seda, paredes, pisos, folhas de amoreira, picadeira de folhas e exposição ao ar (ambiente dechocadeira). Para isto, foi utilizada uma seringa de $50 \mathrm{~mL}$ apresentando uma superfície de dimensão conhecida, de fundo cortado, contendo os meios de cultivo AN e AS, distintamente. As coletas foram realizadas pressionando-se delicadamente a convexidade do meio decultura, presentena seringa, diretamente sobre a superfície a ser amostrada. O procedimento de pressão foi de dez segundos, mantendo-se a seringa imóvel. Em seguida, o meio de cultura foi cortado em fatia aproximada de $1 \mathrm{~cm}$ e colocado dentro da placa de Petri.

Realizadas as coletas, as placas foram identificadas, vedadas e transportadas para o Laboratório do Polo do Centro Oeste em Bauru, SP, incubadas em estufa tipo B.O.D. à temperatura de $25^{\circ} \mathrm{C}$, por um período de 48 horas. Após incubação, o seu crescimento foi enumerado em Unidade Formadora de Colônia por placa (UFC/ placa), conforme PelczARet al. (1997) e ALMEIDA; Jorge (2002). Para classificação do grau de contaminação na chocadeira compararam-se os valores médios obtidos com o padrão de Sadler, apresentado na Tabela 1 (Di FABIO, 1990).

Tabela 1 - Tabela de Sadler.

\begin{tabular}{lcc}
\hline Classificação & $\begin{array}{c}\mathrm{N}^{\circ} \text {. médio de } \\
\text { colônias de } \\
\text { bactérias }\end{array}$ & $\begin{array}{c}\mathrm{N}^{\mathrm{o}} \text {. médio de } \\
\text { colônias de } \\
\text { fungos }\end{array}$ \\
\hline Excelente & $0-10$ & 0 \\
Bom & $11-25$ & $1-3$ \\
Médio & $26-46$ & $4-6$ \\
Ruim & $47-66$ & $7-10$ \\
Muito ruim & $67-86$ & $11-12$ \\
Péssimo & + de 87 & + de 13 \\
\hline
\end{tabular}




\section{RESULTADOS E DISCUSSÃO}

O número médio de avaliações durante o experimento para bactérias e fungos em pontos pré-determinados da chocadeira encontra-senas Tabelas numeradas de 2 a 7. Os índices de contaminações bacterianas e fúngicas observados não foram elevados nos locais onde foram realizadas as exposições das placas ao ar. Para as bactérias, em 18 (100\%) das avaliações todas foram classificadas como excelentes tanto na presença quanto na ausência do bicho-da-seda (antes e após inicio da criação) e, para os fungos, $5(83,3 \%)$ das avaliações foram classificadas como boas na presença do bicho-da-seda (boas antes) e 3 (50\%) na ausência (boas após).

Nas amostras bacterianas, 9 (50,0\%) das avaliações no piso foram classificadas como contaminação péssima. Para fungo, as maiores contaminações (classificação péssima) foram obtidas no piso $(100,0 \%)$ ena picadeira $(100,0 \%)$, principalmentequandoseanalisou na presença do bicho-da-seda. Ambos, pisoe máquina picadeira de folhas, foram considerados os pontos críticos da chocadeira. Portanto, o planejamento do fluxo de trânsito dentro da chocadeira deve restringir ao estritamente necessário à realização das tarefas. Além de grande quantidade de micro-organismos no local indicar que há necessidade de uma melhor higienização do piso e máquina picadeira.

Em $13(72,2 \%)$ das bactérias e $6(100 \%)$ dos fungos, as avaliações de folhas foram classificadas como contaminação péssima. Em 5 (83,3\%) das enterobactérias, as avaliações de folhas foram classificadas como contaminação muito ruim. O pouco conhecimento das condições dos ramos de amoreira trazidos do campo, sem qualquer controle sobre a contaminação, pode consistir em foco de infecção em potencial. Martin; Travers (1989) e OHBa (1996) verificaram presença de Bacillus thuringiensis em folhas de amoreira com frequência relativamente alta, evidenciando que esta população é abundante, ocorrendo naturalmente no ambiente sericícola. Isto ocorre devido, principalmente, à proliferação de cadáveres de bicho-da-seda doentes, confirmando observação de MARGATHO et al. (2008) que detectaram este agente como causa da doença em criações comerciais de bicho-da-seda.

No ambiente sericícola, a temperatura e a umidade são de dificil controle e os esporos de fungos, que adentram as instalações através dos resíduos e materiais contaminados como observado neste trabalho, podem disseminar rapidamente para todo o ambiente mesmo sendo adotados programas sanitários adequados. Entre as doenças larvárias de origem fúngica, a aspergilose foi descrita como uma das principais enfermidades na exploração comercial de bicho-da-seda, acometendo lagartas jovens durante a criação na chocadeira, com alto índice de mortalidade (Tinoco et al., 2000). Também, em condições inadequadas de criação, principalmente umidade elevada, ocorre contaminação por Beauveria bassiana, mais conhecida como calcinose (PitTA et al., 1990; MARGATHO et al., 1996).

Tabela 2 - Classificação do grau de contaminação por fungos em diferentes locais de uma chocadeira, na presença do bicho-da-seda, tendo em vista o número e a porcentagem de avaliação.

\begin{tabular}{|c|c|c|c|c|c|c|}
\hline \multirow{3}{*}{ Classificação } & \multicolumn{6}{|c|}{ Procedência } \\
\hline & \multicolumn{4}{|c|}{ Chocadeira } & \multirow{2}{*}{ Picadeira } & \multirow{2}{*}{ Folha } \\
\hline & Piso & Parede & Bicho & Ar-Exposição & & \\
\hline Excelente & 0 & $5(83,3 \%)$ & 0 & $1(16,7 \%)$ & 0 & 0 \\
\hline Bom & 0 & $1(16,7 \%)$ & 0 & $5(83,3 \%)$ & 0 & 0 \\
\hline Médio & 0 & 0 & 0 & 0 & 0 & 0 \\
\hline Ruim & 0 & 0 & 0 & 0 & 0 & 0 \\
\hline Muito ruim & 0 & 0 & 0 & 0 & 0 & 0 \\
\hline Péssimo & $6(100,0 \%)$ & 0 & $6(100,0 \%)$ & 0 & $6(100,0 \%)$ & $6(100,0 \%)$ \\
\hline Total & 6 & 6 & 6 & 6 & 6 & 6 \\
\hline
\end{tabular}

Tabela 3 - Classificação do grau de contaminação por fungos em diferentes locais de uma chocadeira, na ausência do bicho-da-seda, tendo em vista o número e a porcentagem de avaliação.

\begin{tabular}{lcccc}
\hline \multirow{2}{*}{ Classificação } & \multicolumn{4}{c}{ Procedência } \\
\cline { 2 - 4 } & Piso & Chocadeira & \multirow{2}{*}{ Picadeira } \\
\cline { 2 - 4 } Excelente & 0 & Parede & Ar-exposição & $3(50,0 \%)$ \\
Bom & 0 & $2(66,7 \%)$ & $2(33,3 \%)$ & $1(16,7 \%)$ \\
Médio & 0 & $3(50,0 \%)$ & $1(16,7 \%)$ & 0 \\
Ruim & 0 & 0 & $1(16,7 \%)$ & 0 \\
Muito ruim & 0 & 0 & 0 & $1(16,7 \%)$ \\
Péssimo & $6(100,0 \%)$ & 0 & 0 & 6 \\
\hline Total & 6 & 6 & 6 & 6 \\
\hline
\end{tabular}


Tabela 4 - Classificação do grau de contaminação por bactérias em diferentes locais de uma chocadeira, na presença do bicho-da-seda, tendo em vista o número e porcentagem de avaliação.

\begin{tabular}{lcccccc}
\hline \multirow{2}{*}{ Classificação } & \multicolumn{9}{c}{ Procedência } & \multirow{2}{*}{ Picadeira } & \multirow{2}{*}{ Folha } \\
\cline { 2 - 5 } & \multicolumn{7}{c}{ Piso } & Parede & Bicho & Ar-exposição & & \\
\cline { 2 - 5 } Excelente & $2(27,8 \%)$ & $18(100,0 \%)$ & $4(22,2 \%)$ & $18(100,0 \%)$ & $2(11,1 \%)$ & 0 \\
Bom & $2(11,1 \%)$ & 0 & $3(16,7 \%)$ & 0 & $4(22,2 \%)$ & $3(16,7 \%)$ \\
Médio & $1(5,5 \%)$ & 0 & $3(16,7 \%)$ & 0 & $4(22,2 \%)$ & $1(5,5 \%)$ \\
Ruim & 0 & 0 & $2(11,1 \%)$ & 0 & $3(16,7 \%)$ & $1(5,5 \%)$ \\
Muito ruim & $1(5,5 \%)$ & 0 & $3(16,7 \%)$ & 0 & $1(5,5 \%)$ & 0 \\
Péssimo & $9(5,00 \%)$ & 0 & $3(16,7 \%)$ & 0 & $4(22 ; 2 \%)$ & $13(72,2 \%)$ \\
\hline Total & 18 & 18 & 18 & 18 & 18 & 18 \\
\hline
\end{tabular}

Tabela 5 - Classificação do grau de contaminação por bactérias em diferentes locais de uma chocadeira, na ausência do bicho-da-seda, tendo em vista o número e porcentagem de avaliação.

\begin{tabular}{lcccc}
\hline \multirow{2}{*}{ Classificação } & \multicolumn{3}{c}{ Procedência } \\
\cline { 2 - 4 } & Piso & Chocadeira & \multirow{2}{*}{ Picadeira } \\
\cline { 2 - 4 } Excelente & $8(44,4 \%)$ & $18(100,0 \%)$ & $18(100,0 \%)$ & $9(50,0 \%)$ \\
Bom & $6(33,3 \%)$ & 0 & 0 & $3(16,7 \%)$ \\
Médio & $3(16,7 \%)$ & 0 & 0 & $3(16,7 \%)$ \\
Ruim & $1(5,5 \%)$ & 0 & 0 & 0 \\
Muito ruim & 0 & 0 & 0 & 0 \\
Péssimo & 0 & 0 & 0 & $3(16,7 \%)$ \\
\hline Total & 18 & 18 & 18 & 18 \\
\hline
\end{tabular}

Tabela 6 - Classificação do grau de contaminação por enterobactérias em diferentes locais de uma chocadeira, tendo em vista o número e porcentagem de avaliações, na presença do bicho-da-seda.

\begin{tabular}{|c|c|c|c|c|c|c|}
\hline \multirow{3}{*}{ Classificação } & \multicolumn{6}{|c|}{ Procedência } \\
\hline & \multicolumn{4}{|c|}{ Chocadeira } & \multirow{2}{*}{ Picadeira } & \multirow{2}{*}{ Folha } \\
\hline & Piso & Parede & Bicho & Ar- exposição & & \\
\hline Excelente & $5(83,3 \%)$ & $6(100,0 \%)$ & $5(83,3 \%)$ & $6(100,0 \%)$ & $4(66,6 \%)$ & $1(16,6 \%)$ \\
\hline Bom & $01(16,6 \%)$ & 0 & 0 & 0 & 0 & 0 \\
\hline Médio & 0 & 0 & 0 & 0 & 0 & 0 \\
\hline Ruim & 0 & 0 & 0 & 0 & $2(33,3 \%)$ & 0 \\
\hline Muito ruim & 0 & 0 & $1(16,6 \%)$ & 0 & 0 & $5(83,3 \%)$ \\
\hline Péssimo & 0 & 0 & 0 & 0 & 0 & 0 \\
\hline Total & 6 & 6 & 6 & 6 & 6 & 6 \\
\hline
\end{tabular}

Tabela 7 - Classificação do grau de contaminação por enterobactérias em diferentes locais de uma chocadeira, tendo em vista o número e porcentagem de avaliações, na ausência do bicho-da-seda.

\begin{tabular}{lcccc}
\hline \multirow{2}{*}{ Classificação } & \multicolumn{3}{c}{ Procedência } \\
\cline { 2 - 4 } & Piso & Chocadeira & \multirow{2}{*}{ Picadeira } \\
\cline { 2 - 5 } Excelente & $6(100,0 \%)$ & $6(100,0 \%)$ & $6(100,0 \%)$ & $6(100,0 \%)$ \\
Bom & 0 & 0 & 0 & 0 \\
Médio & 0 & 0 & 0 & 0 \\
Ruim & 0 & 0 & 0 & 0 \\
Muito ruim & 0 & 0 & 0 & 0 \\
Péssimo & 0 & 0 & 0 & 0 \\
\hline Total & 6 & 6 & 6 & 6 \\
\hline
\end{tabular}

Em sericicultura, o controle de doenças já estabelecidas é uma tarefa difícil e praticamente inviável economicamente, portanto, a adoção de medidas preventivas é condição primordial. O trabalho na chocadeira envolve grande número de seres vivos em espaço reduzido, com ambiente fechado, 
caracterizando uma alta densidade populacional, aliado à uma alta rotatividade com entradas e saídas constantes de larvas e pessoas. Estes fatores inerentes à chocadeira são condições favoráveis para a ocorrência de problemas sanitários (OKINO, 1982; FonseCA; FonSECA, 1988; TinOCO et al., 2000; TAKAHASHI et al., 2001).

A pouca disponibilidade de desinfetantes eoutros produtos que não sejam tóxicos às lagartas é outro fator a ser considerado. Os desinfetantes químicos de uso em Sericicultura apresentam restrições, em virtude do risco de intoxicação das lagartas, limitando bastante as opções de produtos disponíveis no mercado (PоRто; Окамото, 2000).

A produção de resíduo numa chocadeira é considerável e crítica, pois trata-se de material extremamente perecível, excelente substrato para crescimento de micro-organismos, podendo ser um foco de doença dentro da chocadeira. Durante a limpeza e desinfecção deve ser retirado o máximo de material residual para que o desinfetante atue com eficiência.

O crescimento de bactérias e fungos após o início da criação indica a quantidade de micro-organismos que as lagartas estão sendo expostas, mesmo que na sua maioria elas não sejam entomopatogênicas. E por melhor que seja o sistema de desinfecção e higienização na chocadeira, as lagartas sempre vão estar expostas a um nível considerável e, quando classificadas dentro do padrão péssimo, pode ocorrer comprometimento da qualidade e do desenvolvimento do bicho-da-seda, comprometendo a produção de casulos.

Com base nos resultados encontrados, recomenda-se que a avaliação da qualidade sanitária da chocadeira deve ser realizada periodicamente, através de monitoramento microbiológico a fim de estabelecer estratégias sanitárias eficientes, necessitando, para tanto conhecer a intensidade da contaminação ambiental e a eficácia dos processos de limpeza e desinfecção executados na chocadeira.

\section{CONCLUSÕES}

As superfícies do piso, da picadeira e das folhas de amoreira são os locais de maior contaminação no interior chocadeira;

A limpeza e desinfecção após a criação reduziu a quantidade de micro-organismos presentes na superfície da chocadeira, sendo que para os fungos, apenas na picadeira;

Em nenhum momento da criação, tanto com ou sem bicho-da-seda, observou-se ausência de crescimento de colônias bacterianas e fúngicas na chocadeira.

\section{REFERÊNCIAS}

ALMEIDA, K.B.; JORGE, A.O.C. Avaliação de desinfecção de superfície em cadeira odontológica. Revista Biociência, v.8, n.1, p.19-27, 2002. Disponível em: <http:// periodicos.unitau.br/ojs-2.2/index.php/biociencias/article/viewFile/53/31>. Acesso em: 31 mar. 2010.

ALMEIDA, A.M.; MARGATHO, L.F.F.; SANCHES, M.M.; GARCIA, M.J.M.; OKAMOTO, F.; IKUNO, A.A. Influência da contaminação ambiental por microrganismos em chocadeiras, sirgarias e depósito de folhas de amoreira utilizado em criações de bicho-da-seda. Revista Arquivos do Instituto Biológico, v.70, p125, 2003. Suplemento. Trabalho apresentado na REUNIÃO ANUAL DO INSTITUTO BIOLÓGICO, 16., 2003, São Paulo. Resumo.

DI FABIO, J. Higiene e controle de qualidade no incubatório. In: FUNDAÇÃO APINCO DE CIÊNCIAS E TECNOLOGIA AVÍCOLAS. Curso de atualização em incubação. Campinas: Arbor Acres Farm, 1990. p.51-60.

FONSECA, A.S.; FONSECA, T.C. Doenças do bichoda-seda. In: FONSECA, A.S.; FONSECA T.C. Cultura da amoreira e criação do Bicho-da-seda, Sericicultura. São Paulo: Nobel, 1988. p.179-200.

GAMA, N.M.S.Q.; SANTIN, E.; TUCCI, E.C.; PAULILLO, A.C. Avaliação da ação de desinfetantes em nascedouros. In: CONFERÊNCIA APINCO DE CIÊNCIA E TECNOLOGIA AVÍCOLAS, 1999, São Paulo, SP. Resumos. São Paulo, 1999. p.14.

HABIB, M.E.M.; ANDRADE, C.F.S. Bactérias Entomopatogênicas. In: ALVES, S.B. (Ed). Controle microbiano de insetos. Piracicaba: FEALQ, 1998. p.386-446.

KRISHNASWAMI, S.; NARASIMHANNA, M.N.; SURYANARAYAN, S.K.; SURYANARAYAN, S. Silkworm diseases and pests. In: FOOD AND AGRICULTURE ORGANIZATION. Manual. Rome: FAO, 1973. p.102-129.

MARGATHO, L.F.F.; BALDASSI, L.; PORTUGAL, M.A. Ocorrência de calcinose branca em criações de bichoda-seda no Estado de São Paulo. O Biológico, São Paulo, v.58, n.1, p.33-36, 1996.

MARGATHO, L.F.F.; OKAMOTO, F.; ALMEIDA, A.M.; DE MARCHI GARCIA, M.J. Isolamento, identificação, caracterização e propriedades bioinseticida do Bacillus thurigiensis em criações de bicho-da-seda (Bombyx mori L.) acometidos pela doença de sotto. In: SIMPÓSIO DE CIÊNCIAS APLICADAS À SERICICULTURA, 1., 2008, Maringá, PR. Resumos. Paraná: 2008. p.1-4.

MARTIN, P.A.W.; TRAVERS, R.S. Worldwide abundance and distribution of Bacillus thuringiensis isolates. Applied and Environmental Microbiology, v.55, p.24372442, 1989. 
OHBA, M. Bacillus thuringiensis populations naturally occurring on mulberry leaves: a possible source of the populations associated with silkworm-reaning insectaries. Journal Applied Bacteriology, v.80, p.56-64, 1996.

OKINO, I. Manual de sericicultura. Bauru: CATI, 1982. $80 \mathrm{p}$.

PELCZAR, M.J; CHAN, E.C.S.; KRIEG, N.R. Microbiologia: conceitos e aplicações. 2.ed. São Paulo: Makron Books, Ecologia Microbiana, 1997. p.305-336.

PITTA, G.P.B.; BERGMANN, E.C.; MARTINS, W.R. Estudo de uma doença fúngica do bicho-da-seda. Ecossistema, v.15, p.119-123, 1990.

PORTO, J.A.; OKAMOTO, F. Efeito da aplicação de desinfetante sobre o bicho-da-seda (Bombyx mori L.). Boletim de Indústria Animal, v.57, n.2, p.193-199, 2000.

PRAÇA, L.B; BATISTA, A.C.; MARTINS, E.S. Estirpes de Bacillus thuringiensis efetivas contra insetos das ordens Lepidóptera, Coleóptera e Díptera. Pesquisa Agropecuária Brasileira, v.39, n.1, p.11-16, 2004.
TAKAHASHI, R.; TAKAHASHI, K.M.; TAKAHASHI, L.S. Sericicultura: uma promissora exploração agropecuária. Jaboticabal: FUNEP, 2001. 140p.

TESSARI, E.N.C.; CARDOSO, A.L.S.P.; CASTRO, A.G.M.; KANASHIRO, A.M.I.; ZANATTA, G.F. Avaliação das condições sanitárias de incubatório de pintos de corte. Arquivos do Instituto Biológico, São Paulo, v.69, n.3, p.1-4, 2002

TINOCO, S.T.J; ALMEIDA, R.A.C. Doenças do bicho da seda. In: COORDENADORIA DE ASSISTÊNCIA TÉCNICA INTEGRAL. Manual de sericicultura. Campinas: CATI, 1992. p.46-59. (Manual Técnico, 35).

TINOCO, S.T.J.; PORTO, A.J.; ALMEIDA, A.M.; SOUZA, C.G.; OKAMOTO, F.; OKAWA, H.; ALMEIDA, J.E.; TAKAHASHI, J.N.; MARGATHO, L.F.F.; NAKATA, N.; TAKAHASHI, R.; FONSECA, T.C.; UCHINO, T.; HIGASHIKAWA, T.; SILVA, W.H. Doenças do bicho da seda. In: COORDENADORIA DE ASSISTÊNCIA TÉCNICA INTEGRAL. Manual de sericicultura. Campinas: CATI, 2000. p.35-43. (Manual Técnico, 75).

Recebido em 11/2/11

Aceito em 4/5/12 